\title{
COMPARATIVE EFFECT OF DENOSUMAB VS TERIPARATIDE ON BONE AND ENERGY METABOLISM
}

\author{
Ávila-Rubio V, Novo-Rodríguez C, García-Fontana B, García-Martin A, Reyes-García R, Morales-Santana S, Muñoz-Torres M. \\ Bone Metabolic Unit - Endocrinology Division, University Hospital San Cecilio, Granada - Spain
}

\begin{abstract}
Introduction: Recent studies have demonstrated the role of osteocalcin in energy metabolism regulation having a connection between this and bone metabolism. According to this, anti-osteoporotic drugs may exert different effects on energy metabolism. Thereby, our aim is to evaluate the effects of antiresorptive (Denosumab) and osteoanabolic (Teriparatide) drugs that reduce or increase respectively osteocalcin (OC) levels, on energy and bone metabolism by assessing of undercarboxilated osteocalcin (ucOC), myostatin and sclerostin levels.
\end{abstract}

\begin{abstract}
Methods: We performed a prospective study of three months duration in patients with postmenopausal osteoporosis who are treated with two different antiosteoporotic drugs: A. dose of $60 \mathrm{mg}$ Denosumab semiannually $(n=22)$ compared to B. $20 \mu \mathrm{g}$ Teriparatide subcutaneous daily ( $n=$ 16). We measured the percent change from baseline in serum ucOC, sclerostin and myostatin levels as main parameters of study, and total $\mathrm{OC}$, P1NP, CTX and PTH as secondary measurements, at first week, first month and third month.
\end{abstract}

\section{Results:}

Table 1. Baseline characteristics

\begin{tabular}{|c|c|c|}
\hline $\begin{array}{l}\text { Baseline characteristics (Mean } \pm \text { SD) } \\
\qquad p>0.05\end{array}$ & $\begin{array}{l}\text { Denosumab Group } \\
(\mathrm{N}=22)\end{array}$ & $\begin{array}{l}\text { Teriparatide Group } \\
\qquad(\mathrm{N}=16)\end{array}$ \\
\hline Age $(\mathrm{yr})$ & $62 \pm 6$ & $63 \pm 10$ \\
\hline $\mathrm{BMI}\left(\mathrm{kg} / \mathrm{m}^{2}\right)$ & $25.8 \pm 3.5$ & $25.1 \pm 4.2$ \\
\hline $\operatorname{GFR}\left(\mathrm{mL} / \mathrm{min} / 1,73 \mathrm{~m}^{2}\right)$ & $79 \pm 16$ & $77 \pm 25$ \\
\hline BMD Femoral neck $\left(\mathrm{g} / \mathrm{cm}^{2}\right)$ & $0.650 \pm 0.077$ & $0.636 \pm 0.077$ \\
\hline BMD Lumbar spine $\left(\mathrm{g} / \mathrm{cm}^{2}\right)$ & $0.746 \pm 0.061$ & $0.700 \pm 0.070$ \\
\hline BMD Total hip $\left(\mathrm{g} / \mathrm{cm}^{2}\right)$ & $0.742 \pm 0.097$ & $0.772 \pm 0.106$ \\
\hline $\begin{array}{l}10 \text { year Probability of Major } \\
\text { Osteoporotic Fracture (\%) }\end{array}$ & $6.2 \pm 5.2$ & $7.5 \pm 5.0$ \\
\hline 10 year Probability of Hip Fracture (\%) & $2.1 \pm 3.3$ & $2.5 \pm 2.9$ \\
\hline Total OC (ng/ml) & $19.2 \pm 7.8$ & $15.9 \pm 6.7$ \\
\hline ucOC (ng/ml) & $5.3 \pm 3.1$ & $6.2 \pm 4.8$ \\
\hline Sclerostin (pmol/L)* & $76.17 \pm 16.15^{\star}$ & $103.80 \pm 14.12^{*}$ \\
\hline Myostatin (pg/ml) & $2629 \pm 592$ & $2671 \pm 550$ \\
\hline $\mathrm{P} 1 \mathrm{NP}(\mathrm{ng} / \mathrm{ml})$ & $49 \pm 22$ & $46 \pm 20$ \\
\hline CTX (ng/ml) & $0.479 \pm 0.213$ & $0.436 \pm 0.134$ \\
\hline PTH (pg/ml) & $53 \pm 17$ & $44 \pm 13$ \\
\hline $25 \mathrm{OHD}(\mathrm{ng} / \mathrm{ml})$ & $39 \pm 12$ & $49 \pm 25$ \\
\hline
\end{tabular}
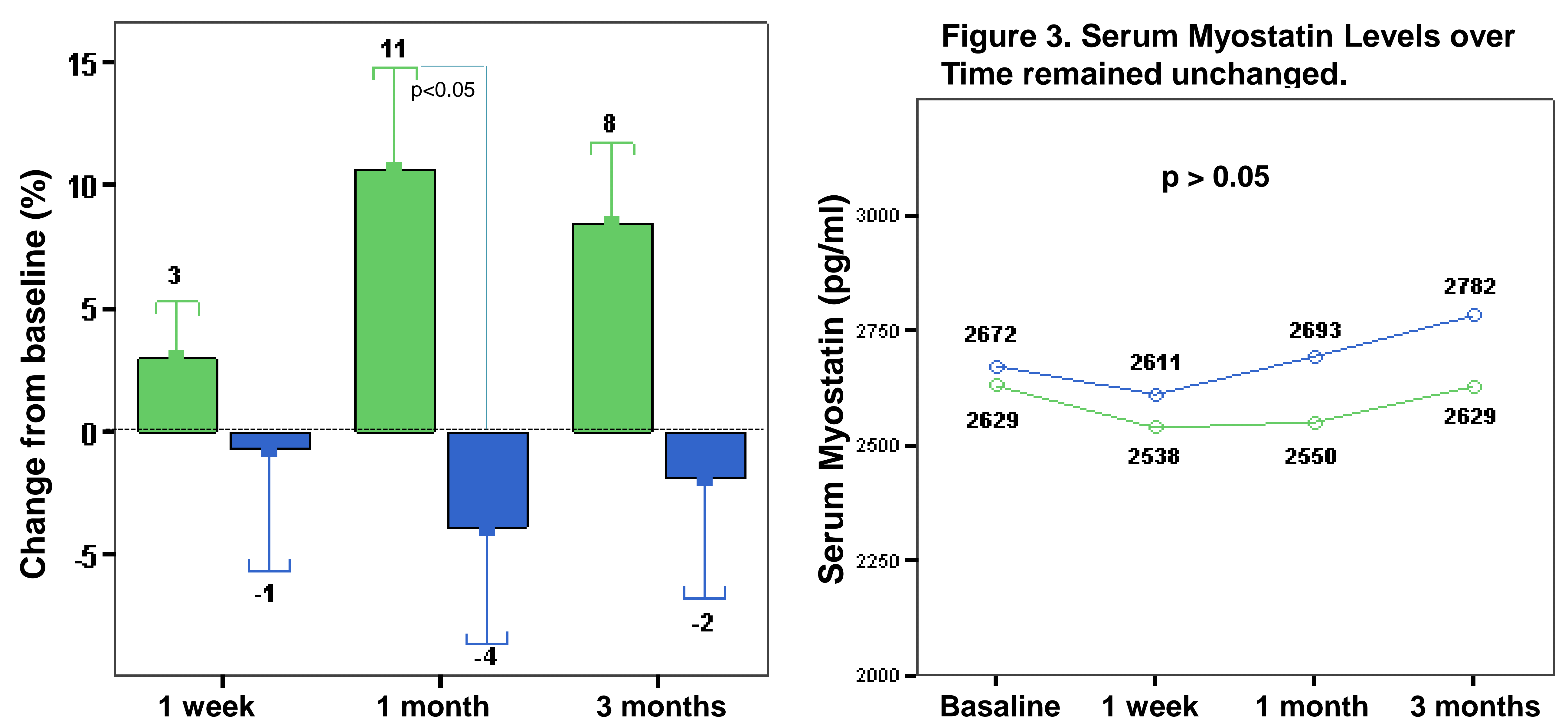

Figure 2. Percent Change over Time in Serum Sclerostin levels. Serum sclerostin levels were increased but not significantly in Denosumab group at first week, first and third month $(2.9 \%, 10.6 \%, 8.5 \%$ respectively) and decreased in Teriparatide group $(0.7 \%, 3.8 \%, 1.9 \%$, respectively, $p>0.05)$; However, there were significant differences between groups at first month $(p=0.03)$.
Figure 1. Percent Change over Time in Serum ucOC levels. Serum ucOC levels were significantly lower in Denosumab group at first and third month $(12.4 \%, 47.8 \%, p<0.05$ respectively) and higher in Teriparatide group at first and third month $(117 \%, p<0.05 ; 87 \%, p=0.06$, respectively) compared to baseline.

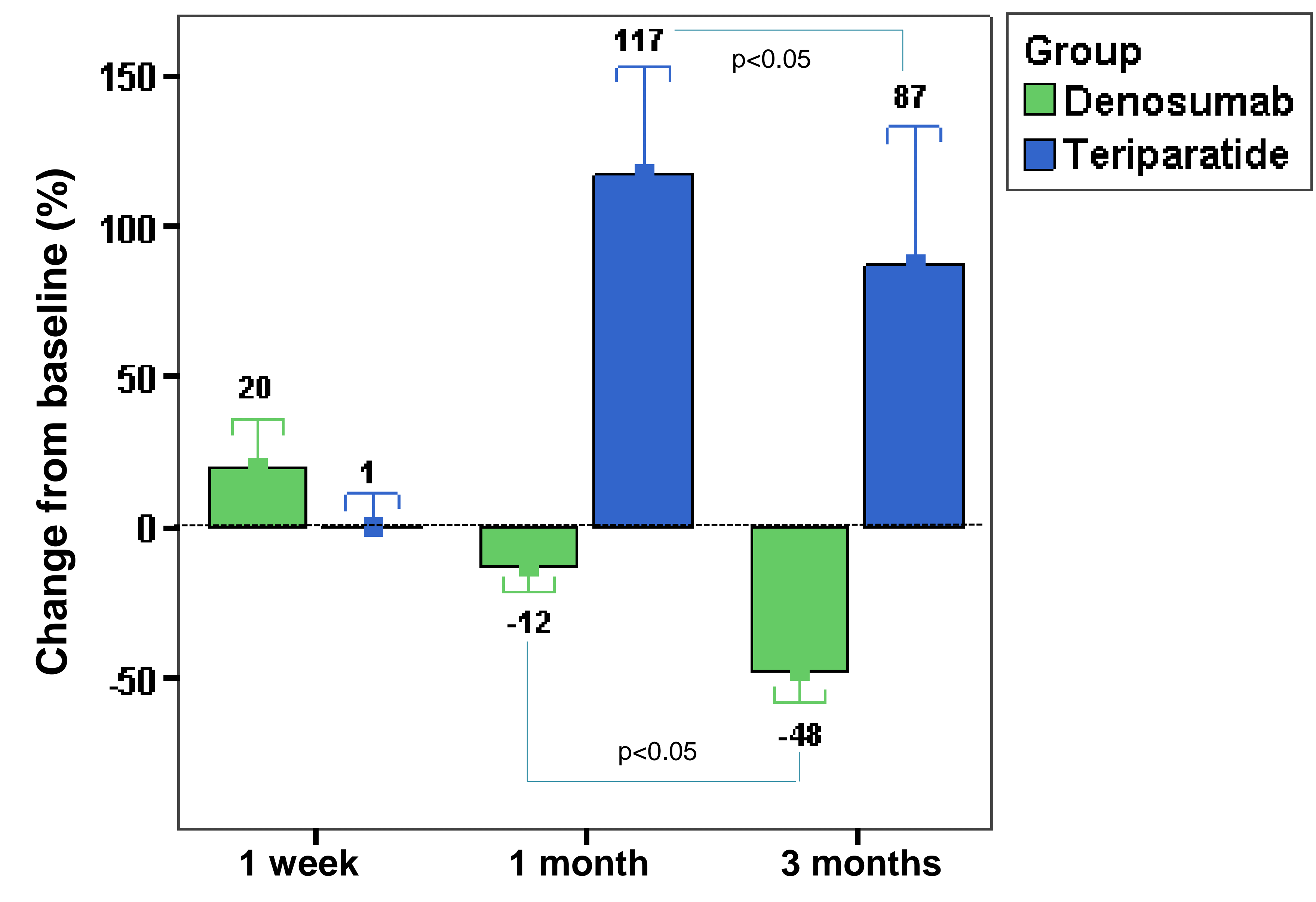

Figure 4. Percent Change over Time in Bone Markers and PTH levels. Bone markers were significantly decreased in Denosumab group $(p<0.01)$ and increased in Teriparatide group $(p<0.05)$; significant differences between groups $(p<0.05)$. PTH levels were significantly higher at first and third month in Denosumab group (65\%, $21.5 \%$, respectively, $p<0.05$ ) with significative differences between groups $(p<0.001)$.

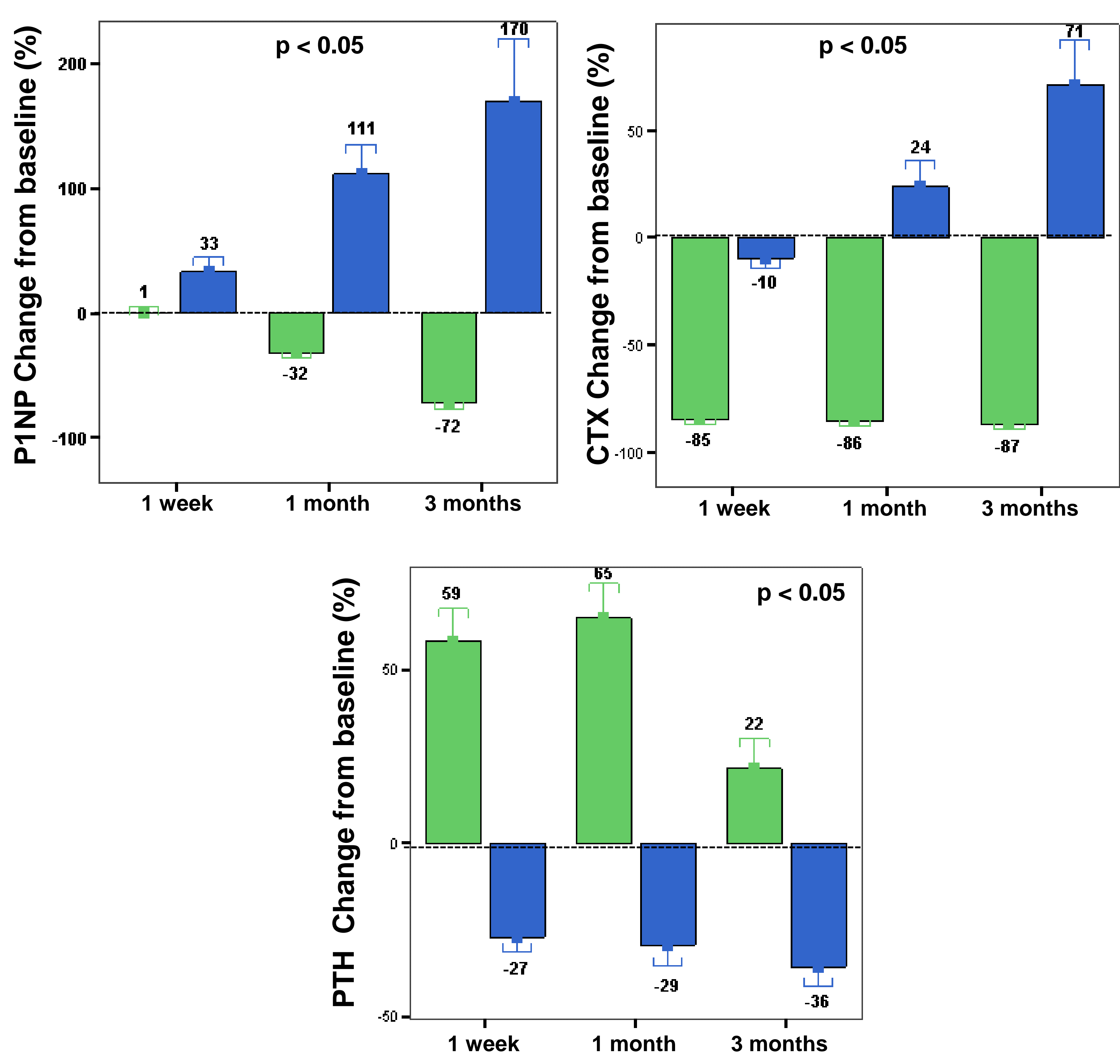

